\title{
Insulin therapy for the non-specialist physician
}

\author{
Author: Svetla Stefanova ${ }^{\mathrm{A}}$
}

Insulin is required for all people living with type 1 diabetes, and may be required in nearly half of those with type 2 diabetes. It is a complex drug, manufactured in several forms and utilised in various regimens and devices. There is evidence that non-specialist professionals lack confidence in insulin therapy and, in addition, insulin-related prescribing errors are common in hospital care. In this article, I summarise commonly used insulin regimens, along with indications and safety considerations when prescribing insulin therapy.

\section{Introduction}

In the UK, there are estimated to be around 4.8 million people living with diabetes, double that from 20 years ago.' The National Diabetes Inpatient Audit (NaDIA) reported that one in six hospital beds are occupied by a person with diabetes. ${ }^{2}$ Almost one-third of these were subject to a medication error, many of which include insulin-related prescribing errors. Insulin is a potent drug, and correct prescribing requires many considerations, including insulin type, regimen, indications and administration. Incorrect prescribing may lead to significant complications, such as hyperglycaemic emergencies or hypoglycaemia. Some non-specialist clinicians lack confidence in insulin therapy and management. ${ }^{3}$ Here, I aim to demystify subcutaneous insulin therapy; I do not cover use of intravenous insulin for diabetic emergencies or acute hyperglycaemia in hospital.

\section{When should I consider insulin therapy?}

People with type 1 diabetes (T1D) have an absolute requirement for insulin, and should be commenced on insulin at diagnosis, or if the diagnosis is suspected. All newly diagnosed patients with T1D should be seen by a diabetes specialist. A standard basal-bolus insulin regimen (see later) is used for almost all people with T1D, which may be moved to continuous subcutaneous insulin infusion (CSII) via insulin pump therapy in certain circumstances.

Around $50 \%$ of the people with type 2 diabetes (T2D) may require insulin, which may be temporary (during acute illness) or permanent if glucose control is inadequate with other agents. ${ }^{4}$ Permanent insulin therapy is usually commenced when there is evidence of beta-cell functional decline, which may present with symptomatic hyperglycaemia (polyuria, polydipsia and

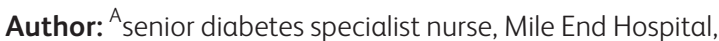
London, UK unintentional weight loss). It may also be found on regular glucose testing, where optimal glucose control is not achieved. Current guidelines advise use of isophane (human) insulin as first choice in T2D including those admitted in hospital. ${ }^{5}$ Other indications for insulin therapy in people with T2D are shown in Box 1.

During the COVID-19 pandemic, increasing numbers of patients have been commenced on insulin in hospital due to acute hyperglycaemia commonly seen with the disease or due to therapy with steroids, exacerbating hyperglycaemia. ${ }^{6}$ In the circumstance of steroid exacerbated diabetes, morning doses of steroids lead to hyperglycaemia particularly later in the day around afternoon or evening. Oral hypoglycaemic drugs (such as metformin or sulphonylurea) may be commenced, but frequently basal isophane insulin given in the morning (starting with 10 units) is required. Rapid increases in dose by $10 \%-20 \%$ daily may be required according to glucose levels.

\section{What insulin type and regimen should I prescribe?}

The centenary of the first use of insulin therapy is approaching; it was first used on a patient with diabetes on 11 January 1922 . Since then, numerous formulations of insulin have been made and ease of use has improved dramatically. Nevertheless, it still needs to be given subcutaneously or intravenously, and progress on alternative methods of insulin delivery has been disappointing.

\section{Key points}

People with type 1 diabetes should start insulin therapy (basal-bolus regimen) at diagnosis.

People with type 2 diabetes may also require insulin as a temporary or permanent therapy.

Insulin is available in various preparations and profiles. Use the right insulin, in the right regimen, for the right patient.

Insulin can lead to hypoglycaemia. Prescribe legibly and without abbreviations.

Insulin therapy is safe and effective only if used correctly and titrated accordingly. Refer to guidelines and seek advice from the diabetes team if in doubt.

KEYWORDS: type 1 diabetes, type 2 diabetes, insulin therapy

DOI: $10.7861 /$ clinmed.2021-0266 
Box 1. Indications for insulin therapy in people with type 2 diabetes
$>$ Foot ulcers
$>$ Recurrent fungal or bacterial infections
$>$ Surgery
Pancreatitis
$>$ Acute coronary syndrome
End-stage renal disease
Enteral feeding
Preconception care and pregnancy
$>$ Ketosis prone diabetes
$>$ Personal preference

Insulin is administered subcutaneously except in hospital emergencies where fixed or variable rate intravenous infusion of insulin (FRIII or VRIII) is required. ${ }^{8}$ It is dispensed in different forms, including vials, cartridges and pre-filled disposable pens. The latter are generally easier to use and may be the preferred patient choice. Insulin cartridges must be used with a compatible reusable insulin pen device. Both disposable and reusable pens need insulin needles for single use with universal fit. $4 \mathrm{~mm}$ or $5 \mathrm{~mm}$ needles are generally recommended.

There are three main types of insulin: animal, human and analogue. Animal insulin (mainly porcine) is of very limited use nowadays. According to their characteristics, insulins are grouped into five main categories. ${ }^{4}$

> Short-acting insulin (human): examples include Actrapid and Humulin S. These are also meal-time insulins, but with a slower onset and longer duration. They are rarely used in basal-bolus regimens nowadays.

> Rapid-acting insulin (analogue): examples include insulin lispro (Humalog) and insulin aspart (NovoRapid). This is a meal-time insulin designed to cover postprandial glucose rises. It is injected before/with food usually as part of basal-bolus insulin regimen.

> Intermediate-acting insulin (human): also referred as isophane or NPH insulin; examples include Insulatard and Humulin I. This is a background insulin, administered once or twice daily, usually in combination with oral medication in T2D. It may be given with rapid acting insulin in people with $T 2 \mathrm{D}$ with inadequate control.

> Long-acting and ultralong-acting insulin (analogue): examples include insulin glargine (Lantus), insulin detemir (Levemir) or insulin degludec (Tresiba). These are used as a once or twice daily injection as part of the basal-bolus insulin regimen. They have a flatter profile than human/intermediate insulins, and may reduce hypoglycaemia risk. Long-acting analogues are used first line in T1D and may be used second line in T2D if hypoglycaemia is an issue.

> Premixed (biphasic) insulin (human or analogue): a mixture of rapid/short-acting with intermediate-acting insulins; examples include NovoMix 30, Humulin M3, Humalog Mix 50. This is used in people with T2D who need prandial cover but only wish to inject twice daily.

Information on insulin medicinal forms, profiles and devices can be found in the Diabetes UK guide. ${ }^{9}$ Table 1 shows profiles and medicinal forms of some common insulins used in the UK.
There are three main regimens with the insulins outlined earlier.

> Once/twice daily basal (intermediate- or long-acting insulin) given with tablets: used in inadequately controlled $T 2 \mathrm{D}$ requiring initial insulin therapy. It is usually given at bedtime but can be given in the morning if required.

$>$ Twice daily fixed mixtures (premixed): given for people with T2D requiring intensified insulin therapy. Common mixtures are $30 / 70$ (30\% short or rapid acting and $70 \%$ intermediate acting), with a dose given in the morning before breakfast and in the evening before evening meal. This regimen is relatively inflexible, and requires regular meal-times.

> Basal-bolus (intermediate or long acting with rapid insulin): used in most people with T1D and some people with T2D. This is the most physiological regimen, with mealtime rapid-acting insulin given pre-meal, and once or twice daily basal insulin given as a background.

\section{What dose should I start with?}

Evidence about starting dose of subcutaneous insulin is somewhat limited. The consensus is to start low and increase gradually based on patterns in glucose levels. The Royal College of Nursing (RCN) recommends starting 10 units once daily basal insulin, or twice daily insulin regimens can be commenced with 10-12 units twice a day. Insulin starting doses can also be calculated on a body weight estimate using $0.3-0.5$ units per kg per day. ${ }^{4}$

If the patient is on a VRIII, a total daily dose of insulin may be estimated from the preceding 24 hours of insulin delivery. Depending on the regimen started, this dose can be started as a total daily dose if once daily basal insulin is required. If changing from a VRIII to a basal-bolus regimen, approximately $50 \%$ of the total daily dose (TDD) should be given as basal, and the remaining $50 \%$ given as evenly split boluses with each meal. ${ }^{8}$ For instance, 42 units TDD insulin requirement will be split into a basal dose of 21 units $(42 \div 2=21)$ and bolus dose of 7 units with each meal $(21 \div 3=7)$. Daily glucose monitoring is required to allow insulin dose titration. Patients will need to be taught self-monitoring of blood glucose (SMBG) and insulin administration ideally by the inpatient diabetes specialist nurse. Most patients commencing new insulin regimens should be testing at least four times daily; fasting, pre-meal and pre-bed. Reasonable inpatient targets are between 6 and $10 \mathrm{mmol} / \mathrm{L}$, with the avoidance of hypoglycaemia, although more lenient targets should be considered for frail patients with comorbidities.

\section{How do I adjust insulin doses?}

Adjustment of insulin doses is relatively simple, but infrequently done. Some guidelines have been developed to support professionals in insulin dose titration. ${ }^{4}$

Some general rules are:

$>$ titrate insulin doses according to SMBG profiles over a few days

$>$ titrate insulin dose in 2-4 units increments at a time, or by $10 \%$ for higher doses ( $>40$ units)

$>$ reduce insulin dose by $10-20 \%$ if hypoglycaemia occurs

$>$ set up individualised targets

$>$ review in 3-4 days.

The following case studies suggest some typical ways of adjusting insulin therapy. 
Table 1. Profiles and medicinal forms of some common insulins used in the UK

\begin{tabular}{|c|c|}
\hline \multicolumn{2}{|l|}{ Human synthetic insulin } \\
\hline Short acting & $\begin{array}{l}>\text { Absorbed quickly and lasts for several hours } \\
>\text { Onset } 30-45 \text { minutes, peak } 2-4 \text { hours and duration up to } 6 \text { hours } \\
>\text { Eg Humulin S, Humulin R and Actrapid }\end{array}$ \\
\hline Intermediate acting / isophane & $\begin{array}{l}>\text { Absorbed slowly and lasts for up to } 24 \text { hours } \\
>\text { Onset } 1-2 \text { hours, peak } 4-8 \text { hours and duration } 16-18 \text { hours } \\
>\text { Eg Insulatard, Humulin I and Insuman Basal }\end{array}$ \\
\hline Fixed mixtures / pre-mixed & $\begin{array}{l}>\text { Mixture of short- and intermediate-acting insulin (biphasic human insulin) } \\
>\text { Onset 30-45 minutes, peak 2-4 hours and duration 14-16 hours } \\
>\text { Eg Humulin M3, Insuman Comb } 15 \text { and Insuman Comb } 50\end{array}$ \\
\hline \multicolumn{2}{|l|}{ Analogue insulin } \\
\hline Rapid acting & $\begin{array}{l}>\text { Absorbed more rapidly and with shorter duration than the short-acting insulin } \\
>\text { Onset } 10-20 \text { minutes, peak 1-3 hours and duration 3-5 hours } \\
>\text { Eg NovoRapid (aspart), Humalog (lispro) and Apidra (glulisine) }\end{array}$ \\
\hline Ultra-rapid acting & $\begin{array}{l}>\text { More rapid than rapid-acting insulin } \\
>\text { Onset } 4 \text { minutes } \\
>\text { Eg Fiasp (aspart) }\end{array}$ \\
\hline Long acting & $\begin{array}{l}>\text { Absorbed slower than intermediate insulin providing a flatter profile } \\
>\text { Onset } 1-2 \text { hours, no peak and duration up to } 24 \text { hours } \\
>\text { Eg Levemir (detemir), Lantus (glargine), and Abasaglar and Semglee (glargine biosimilars) }\end{array}$ \\
\hline Ultra-long acting & $\begin{array}{l}>\text { Absorbed slower than intermediate insulin providing a flatter profile } \\
>\text { Onset } 1-2 \text { hours, no peak and duration } 36-42 \text { hours } \\
>\text { Eg Tresiba (degludec), Toujeo (glargine } 300 \text { units } / \mathrm{mL} \text { ) }\end{array}$ \\
\hline Fixed mixtures / pre-mixed & $\begin{array}{l}>\text { Mixture of rapid- and intermediate-acting insulin } \\
>\text { Onset } 15 \text { minutes, peak 50-90 minutes and duration 14-16 hours } \\
>\text { eg NovoMix 30, Humalog Mix } 25 \text { and Humalog Mix } 50\end{array}$ \\
\hline
\end{tabular}

\section{Case 1}

$\mathrm{Mr} \mathrm{B}$ is a 66-year-old man who is an inpatient with a diabetic foot infection. He takes NPH insulin 18 units at bedtime, and oral gliclazide and metformin at maximum doses. His glucose levels for the last few days are shown in Table 2.

Management: focus on the fasting hyperglycaemia first. Gently increase insulin by 2 units every $2-3$ days until fasting glucose levels are below $8 \mathrm{mmol} / \mathrm{L}$. If daytime hyperglycaemia persists, consider switching to premixed insulin twice daily.

\section{Case 2}

Mrs $S$ is a 61-year-old woman who is recovering from urosepsis. She is on metformin and biphasic 30/70 mixed insulin 46 units with

\section{Table 2. Mr B's glucose levels}

$\begin{array}{llllll}\text { Date } & \text { Breakfast } & \begin{array}{c}\text { Lunch } \\ \text { Day 1 }\end{array} & \begin{array}{c}\text { Evening } \\ \text { meal }\end{array} & \text { Bed } & \text { Comment } \\ \text { Day 2 } & 9.8 & 15.0 & & 10.0 & \begin{array}{l}\text { Pre-lunch level } \\ \text { done after } \\ \text { biscuits and tea }\end{array} \\ \text { Day 3 } & 11.9 & 12.0 & & \\ \text { Day 4 } & 9.5 & & & \\ \text { Day 5 } & 9.5 & & 10.0 & \end{array}$

breakfast and 40 units with dinner. Her glucose levels for the last few days are shown in Table 3.

Management: glucose levels are perhaps too low in the morning, with hypoglycaemia pre-bed, so consider reducing evening dose by $2-4$ units. Higher glucose levels in the day may need a slight increase in morning / breakfast dose by 2-4 units; although, as she recovers, insulin requirements may go down.

\section{Case 3}

$\mathrm{Mr} \mathrm{P}$ is a 42-year-old man treated for pancreatitis. He is on NPH insulin 20 units at bed time and rapid insulin 6 units three times a day before meals. His glucose levels for the last few days are shown in Table 4.

Management: morning hyperglycaemia will require a slight increase in NPH insulin at night by 2 units until fasting glucose

\section{Table 3. Mrs S's glucose levels}

\begin{tabular}{|c|c|c|c|c|c|}
\hline Date & Breakfast & Lunch & $\begin{array}{l}\text { Evening } \\
\text { meal }\end{array}$ & Bed & Comment \\
\hline Day 1 & 6.2 & & 12.3 & & \\
\hline Day 2 & & 11.3 & & 3.5 & $\begin{array}{l}\text { Hypoglycaemia } \\
\text { after dinner }\end{array}$ \\
\hline Day 3 & 5.5 & & 13.5 & & \\
\hline Day 4 & & 12.2 & & 6.0 & \\
\hline Day 5 & 4.8 & & 10.0 & & \\
\hline
\end{tabular}


Fig 1. An example of a correctly written insulin script.

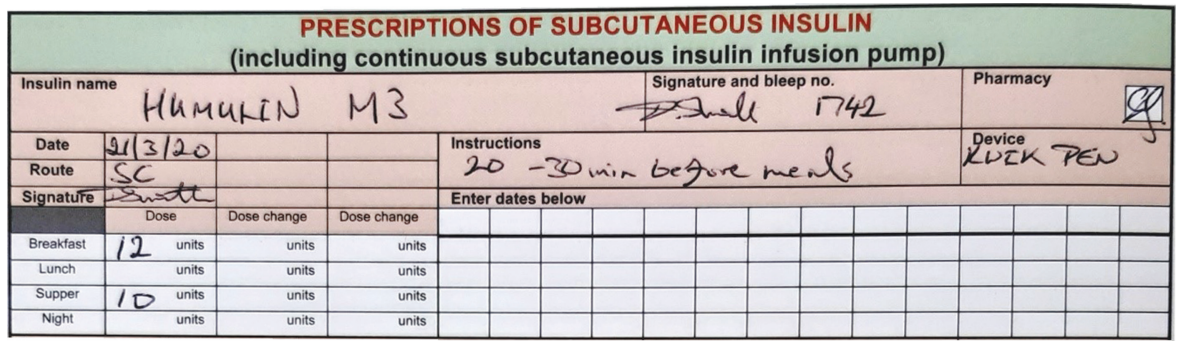

\section{Table 4. Mr P's glucose levels}

$\begin{array}{llllll}\text { Date } & \text { Breakfast } & \begin{array}{c}\text { Lunch } \\ \text { Day 1 }\end{array} & \begin{array}{l}\text { Evening } \\ \text { meal }\end{array} & \text { Bed } & \text { Comment } \\ \text { Day 2 } & 11.1 & 7.5 & 14.0 & & \\ \text { Day 3 } & 9.3 & & 12.0 & 8.0 & \\ & & & & & \begin{array}{l}\text { Declined tests } \\ \text { before lunch and } \\ \text { bedtime }\end{array} \\ \text { Day 4 } & 13.2 & 6.3 & & 8.6 & \\ \text { Day 5 } & 10.1 & & 9.2 & & \end{array}$

is ideally below $8 \mathrm{mmol} / \mathrm{L}$. Pre-evening meal hyperglycaemia suggests more rapid insulin needed at lunch increased by 2 units.

\section{How do I prescribe insulin safety?}

Iatrogenic hypoglycaemia is a common side effect of insulin therapy. Guidelines on managing hypoglycaemia should be readily available in your trust ideally with an easily accessible 'hypo box' on the wards. Fig 1 shows a correct insulin prescription in hospital.

The main points to consider when prescribing insulin are:

> Avoid using terms 'IU', 'U' or 'units' and just write a number on hospital drug charts. This is because the letter ' $U$ ' can be confused with the number ' 0 ' which leads to a 10 -fold prescribing error.

> Prescribe the correct insulin. 'NovoMix' and 'NovoRapid' sound similar but are very different insulins (see earlier). Similarly, Humulin I and Humulin M3 are often mistaken. Check with the patient and their regular prescription.

> Prescribe the correct dose or range of doses; check and double check with the patient. Consider allowing the patient to selfmanage their insulin therapy if they are able to do so.

> Prescribe the correct device and strength. Most insulins have concentration of 100 units/mL (U100). Some have much higher concentration (U200 or U300), so again check with the patient or their normal prescription.

$>$ Consider proactively reducing insulin if oral intake is poor, steroids are being discontinued or there is hepatic or renal impairment.

> NEVER draw insulin out of an insulin pen or Penfill cartridge as it may result in administering a much higher dose due to variable insulin strengths (as earlier).

\section{Conclusion}

Insulin therapy is a lifesaving and life-enhancing treatment for millions of people living with diabetes worldwide. It is used widely in hospital practice and requires careful management and prescribing. While commencing and adjusting insulin therapy is relatively simple, advice should be sought from diabetes specialist inpatient teams when patients require complex insulin regimens or management.

\section{References}

1 DiabetesUK. Diabetes prevalence. London: Diabetes UK, 2019.

2 NHS Digital. National Diabetes Inpatient Audit (NaDIA) England and Wales - 2017. NHS, 2018. https://digital.nhs.uk/data-andinformation/publications/statistical/national-diabetes-inpatientaudit/national-diabetes-inpatient-audit-nadia-2017 [Accessed 19 February 2021].

3 Derr RM, Sivanandy MS, Bronich-Hall L, Rodriguez A. Insulin-related knowledge among health care professionals internal medicine. Diabetes Spectrum 2007;20:177-85.

4 Royal College of Nursing. Starting injectable treatments in adults with type 2 diabetes, 3rd Edn. London: RCN, 2019.

5 National Institute for Health and Care Excellence. Type 2 diabetes in adults: management: NICE guideline [NG28]. NICE, 2020. www.nice. org.uk/guidance/ng28/chapter/Recommendations\#individualisedcare [Accessed 21 February 2021].

6 Association of British Clinical Diabetologists. Concise advice on inpatient diabetes (COVID: diabetes): Guideline for managing DKA using subcutaneous insulin. ABCD, 2020. https://abcd.care/ resource/concise-advice-inpatient-diabetes-during-covid-19-guidelines-managing-dka-using [Accessed 22 February 2021].

7 Diabetes UK. History of insulin. Diabetes UK, 2019. www.diabetes. co.uk/insulin/history-of-insulin.html [Accessed 20 February 2021].

8 Dhatariya K, James J, King MF, Berrington R; On behalf of the Joint British Diabetes Society for inpatient care (JBDS-IP) group and guidelines writing group. Diabetes at the front door. A guideline for dealing with glucose related emergencies at the time of acute hospital admission. Diabetic Medicine 2020;37:1578-89.

9 Diabetes UK. Meds \& kit. Diabetes UK, 2020. www.diabetes.org. uk/resources-s3/2019-11/diabetes-uk-meds-and-kit-2020.pdf [Accessed on 22 February 2021].

Address for correspondence: Ms Svetla Stefanova, Diabetes Centre, Mile End Hospital, Bancroft Road, London E1 4DG, UK. Email: svetla.stefanova@nhs.net 